\title{
An Immuno-Histochemical Assessment of Ki67, P53 Over-Expression in Helicobacter Pylori Positive Gastritis.
}

Karam Turath Tawfeeq ( $\sim$ h.aqeel@alnukhba.edu.iq )

University of Mosul College of Medicine

Elaf Abdulwahhab Hamdi

University of Mosul College of Medicine

Nadwa Subhi Al-azzo

University of Mosul College of Medicine

\section{Research Article}

Keywords: Gastritis, Helicobacter pylori, Ki67, P53, mutations

Posted Date: November 19th, 2021

DOI: https://doi.org/10.21203/rs.3.rs-1070156/v1

License: (c) (i) This work is licensed under a Creative Commons Attribution 4.0 International License.

Read Full License 


\section{Abstract}

Background and Objective: Helicobacter pylori infection of the stomach is a common disease and the resulting changes from it are numerous and deserve to be in the focus of researchers' attention. The aim of this study is to assess the expression of mutant P53 protein and Ki-67 markers in patients with gastritis secondary to Helicobacter pylori.

Methods: Thirty samples with positive Helicobacter pylori gastritis were included in a retrospective study in Mosul / Iraq. The histological parameters were assessed using the Sydney system, then the expression of Ki67 and P53 expression were studied by immunohistochemical methods. The significance level was appointed at (0.05).

Results: Ki67 and P53 expression were found in $83.3 \%$ of the total cases. The study results show that $92 \%$ of positive Ki67, P53 cases had chronic inflammatory cell infiltration, polymorph nuclear cells infiltration, and atrophy. Whereas $96 \%$ of positive Ki67 cases had no metaplasia, $92 \%$ of the positive P53 cases had no metaplasia. The results also showed that only $16 \%$ of the positive Ki67 cases had dysplastic changes, and $24 \%$ of the positive cases of P53 cases were showed dysplasia. moreover, whenever P53 was negative; there is neither metaplasia nor dysplasia in the tissue, this does not apply to Ki67 negative cases.

Conclusions: Ki67, P53 expressions increase with chronicity of Helicobacter pylori-positive gastritis, P53 expression is amplified when atrophy is present in these samples

\section{Introduction:}

Gastritis is defined as inflammation of the stomach mucosa, it could be acute or chronic ${ }^{(1)}$. Chronic gastritis is still common in developing countries ${ }^{(1)}$. Gastritis is believed to affect about $50 \%$ of people in the world and the prevalence increases with age ${ }^{(2)}$.Gastritis might be complicated by bleeding, ulcer, and stomach cancer, so it is worth studying and exploring its causes in order to pave the way for treatment ${ }^{(1)}$.

Although Helicobacter pylori (HP) is one of the most common chronic infections worldwide (about $50 \%$ of the population is infected by HP) and is the commonest cause for gastritis ${ }^{(3)}$, However, almost two thirds of patients with negative HP were found to have gastritis. Other causes of gastritis include ingestion of nonsteroidal anti-inflammatory drugs, smoking, narcotics, alcohol and autoimmune diseases $(4-8)$.

Chronic gastritis is associated with neutrophil infiltration ;with different effects according to HP strain, the aggressive strain will cause atrophic gastritis, in this situation, the lost glands replaced by new immature glandular and epithelial cells look like glands of intestinal tissues and called intestinal metaplasia which is found in end-stage disease and are considered as a premalignant lesions $(9,10)$. 
The long-term presence of HP leads to persistent damage and hyper proliferation of the lining epithelium of stomach, that will lead to an increase in the occurrence of mutations and development of gastric cancer ${ }^{(11)}$. P53 is an important prognostic factor in many tumors, one of them is early gastric adenocarcinoma ${ }^{(12,13)}$. The p53 gene activation occur after damaging the DNA, which in turn leads to cell cycle arrest in phase $\mathrm{G} 1$ and repairs the damaged DNA, or cell apoptosis. Recently, studies have shown that HP infection plays a direct role on p53 mutagenesis in patients with intestinal metaplasia and dysplasia ${ }^{(14,15)}$.

Ki-67 protein expression is linked to cell proliferation, and while it is missing in resting cells, it is present throughout the cell cycle's active stages, making it a perfect biomarker for cell proliferation. ${ }^{(16)}$.Studies showed that expression of Ki-67 is higher in intestinal metaplasia in the specimens with positive HP infection in comparison to negative HP samples, this illustrate the effect of HP infection on the expression of Ki-67 during the precancerous phases ${ }^{(17-20)}$. The previous findings have shown that the expressions of P53 and Ki67 were associated with each other. However, these markers alone had no diagnostic value $(21,22)$.

Aim: The aim of this study is to assess the mucosal expression of mutant p53 protein and Ki-67 markers in patients with gastritis secondary to HP infection, the results were correlated with the age and gender of the patients and with some histological properties guided by Sydney system .

\section{Materials And Methods:}

\section{Study setting \&design}

At first, all necessary official approvals were obtained before conducting the Mosul research from the College of Medicine of Mosul. Tiny pieces of samples suspected of gastritis were obtained by endoscope in this retrospective study. The cases collected from Nineveh governorate private laboratories and teaching hospitals, then processed in all procedures needed together with data analysis from October 2020 through April 2021. Clinical data was collected including the age, sex.

Histopathology and Immune Staining: At first, H\&E staining was performed for each sample, if the diagnosis of gastritis was established, then searching for availability of HP with Giemsa stain, positive cases of HP gastritis only included in this study. The histological parameters were evaluated using the Sydney system: chronic inflammation, PNM (polymorph nuclear cells), atrophy, metaplasia, in which the cases were divided into 4 grades as follows: - 0: not present, 1: mild, 2: moderate, 3: severe. Dysplasia assessment was added to Sydney system.

After collecting 30 cases of HP positive gastritis, the Ki67 and P53 over-expression were studied by immunohistochemical method using Dako monoclonal antibody for Ki67 and P53 Protein.

Immune-staining assessment: Ki-67 and P53 staining intensity was graded as follows (independently): 0 for negative staining, 1 for mild staining, 2 for moderate staining, and 3 for high staining. ${ }^{(23)}$. The 
staining distribution was categorized as follows:0, < 5\%; 1, 5\% - 25\%; 2, 25\% - 50\%; 3, 50\% - 75\%; 4, > 75\%, and the final score was obtained by multiplying the intensity score by the distribution score. The final results were within the range of $0-12$, scores greater than 4 were considered as positive expression for that marker and less than 4 were considered negative expression for that marker ${ }^{(24)}$.

\section{Statistical analysis}

was done with chi-square test and $(F)$ test as required, using Minitab 18th edition, with $p$-value $<0.05$ used as a significant association in the results.

\section{Results:}

\section{Marker expression}

In this study, 30 patients with HP-positive gastritis were recovered, all samples were antral biopsies, Ki67 expression was found in $83.3 \%$ of the total cases, the same for the P53 marker, in which also $83.3 \%$ of the cases were positive. The detection of Ki67 concordance with P53 was statistically in fair agreement ( $=0.267)$. (Figure -1$)$

\section{Patient's age \& sex}

The age of the patients ranged from 14 to 84 years with mean 46 years \pm 17.2 ( Table 1,2), the largest group of Ki67 positive cases (36\%) were in the age group (42-55) years, again the largest group of P53 positive cases $(40 \%)$ also were in the age group (42-55) years, with significant p-values (0.039) and (0.019), respectively.

$53.3 \%$ of the cases were female with $56 \%$ of the positivity in both markers, while $60 \%$ of negative cases in both markers were males, with no significant p-value (0.409) (Figure 2).

\section{Histological examination}

About 2/3 of cases with positive Ki67 expression had grade 2 or 3 of chronic inflammatory cells, PMN cells infiltrations, atrophy with p-values $(0.014)$ that were significant, $(0.227)$ not significant and $(0.131)$ not significant, respectively. Although $96 \%$ of them did not have metaplasia with significant $p$-value (0.013). On the other hand, more than half of the negative Ki67 cases had no infiltration of PMN cells, no atrophy, no metaplasia, and only $20 \%$ of them had no infiltration of

chronic inflammatory cells (Table 3 ).

The study results show that $92 \%$ of positive P53 cases had chronic inflammatory cells, PMN cells infiltration and atrophy with p-values (0.020) significant, $(0.110)$ non- significant and $(0.078)$ nonsignificant, respectively. The opposite was true for metaplasia, in which $92 \%$ of positive cases of P53 cases had no metaplasia with a significant p-value (0.034), (Table 4). 
Lastly, whilst $16 \%$ of positive Ki67 cases were only showed dysplastic changes, $24 \%$ of positive P53 cases were showed dysplasia, with non-significant p-values (0.074) and (0.467) respectively (figure 3 ).

\section{Discussion:}

Many researchers have studied the expression of Ki67 \& P53 in both positive and negative HP gastritis, gastric ulcer, and cancer. In this study, the expression of Ki67 \& P53 were assessed only in positive HP gastritis and the expression of Ki67 \& P53 were detected in 83.3\% of cases, a higher percentage more than many other studies, such as: Azza et al ${ }^{(25)}$ study in which Ki67 \& P53 expression were $54.5 \%, 72.7 \%$ respectively, Cesar et al ${ }^{(26)}$ study in which P53 expression was $45 \%$, Afaf et al ${ }^{(27)}$ study in which P53 expression was $32.7 \%$, while in Morales-Fuentes et al ${ }^{(28)}$ study, the P53 expression was $91 \%$ which is more than this study. The differences could be due to the different sample size of the cases taken by the studies, different genetic background, variation in food types between the nations, etc. It is worth saying that despite the similarity of the overall percentage of positive cases for the two markers in the present study, there were positive cases for Ki67 and negative for P53 and vice versa in six cases, and only two cases were negative for both markers.

In this study, the age range from 14-84 years with mean 46 years \pm 17.2 , male to female ratio was $7: 8$, in Morales-Fuentes et al ${ }^{(28)}$ study the range of age was 55-81 years and male to female ratio 5:6, while in Azza et al ${ }^{(25)}$ study the patients mean age was 53 years \pm 5.1 and male to female ratio $1.75: 1$, and in Zainab et al ${ }^{(29)}$ study the patients' age range was 11 - 82 years (mean of 46.5 years) with a male to female ratio of 1.38:1. Ki67 \& P53 expressions in this study were significantly detected more in age group (42-55) years, also the expression of both Ki67 \& P53 were seen in females more than males .This discrepancy of results among different studies might be due to bias in data collection of some researches.

In the present study, $86.2 \%$ of the studied cases with chronic infiltration of inflammatory cells showed positive Ki67 \& P53 expression, while in the study by Afaf et al ${ }^{(27)} 32.7 \%$ of these cases had positive expression of P53.

Ki67 \& P53 were expressed in $92 \%$ of cases with infiltration of PMN cells, while in the study by Afaf et al (27) $66.7 \%$ of these cases had positive expression of P53.

Furthermore, $92.3 \%$ of cases with atrophy had positive Ki67 \& P53 expression, while in the study by Afaf et al ${ }^{(27)} 26.1 \%$ only of the cases had positive P53 expression.

Although they are few detected in this study, all cases with intestinal metaplasia showed positive P53 expression, and only half of them showed Ki67 expression, while in Mahmoudzadeh et al ${ }^{(23)}$ study $60 \%$, $55 \%$ only of these cases had positive P53, Ki67 expression respectively, while in Afaf et al ${ }^{(27)}$ study $31.7 \%$ only of these cases had positive P53 expression. On the contrary to the results of this study, Forones et al. ${ }^{(30)}$ found in their study that all samples with intestinal metaplasia had negative expression 
of P53, and they supposed that the mutation of P53 occur in latter stages of gastric carcinogenesis. The explanation of the reason for the lack of the presence of the intestinal metaplasia in large number of cases in this research is belong to exclusion of negative cases of HP, and as it is known, this bacterium does not colonize in the intestinal metaplastic tissues.

Regarding the cases with dysplasia, again all of them showed positive expression of P53, while only $2 / 3$ of them showed Ki67expression, while in Mahmoudzadeh et al ${ }^{(23)}$ study $57.89 \%, 26.31 \%$ only of these cases had positive expression respectively.

\section{Conclusions:}

Ki67, P53 expressions increase with chronicity of HP positive gastritis,

P53 expression is amplified when atrophy is present in HP positive gastritis samples.

\section{Declarations:}

\section{Acknowledgment:}

The researchers thank Dr. Hala Thanoun (a former resident of pathology) for her assistance in collecting pathological samples from the laboratories.

\section{Conflict of interest:}

The authors declare that they have no conflict of interest.

\section{References}

1. W. Fischbach PM, P. Lynen Jansen, W. Bolten, J. Bornschein, S. Buderus et al. S2k-guideline Helicobacter pylori and gastroduodenal ulcer disease. Z Gastroenterol. 2016 (54):327-63.

2. Sipponen P, Maaroos HI. Chronic gastritis. Scandinavian journal of gastroenterology. 2015 Jun;50(6):657-67. PubMed PMID: 25901896.

3. Kim KM, Oh YL, Ko JS, Choe YH, Seo JK. Histopathology and expression of Ki-67 and cyclooxygenase-2 in childhood Helicobacter pylori gastritis. Journal of gastroenterology. 2004;39(3):231-7. PubMed PMID: 15064999.

4. Kamimura K, Kobayashi M, Sato Y, Aoyagi Y, Terai S. Collagenous gastritis: Review. World journal of gastrointestinal endoscopy. 2015 Mar 16;7(3):265-73. PubMed PMID: 25789098.

5. Kulnigg-Dabsch S. Autoimmune gastritis. Wiener medizinische Wochenschrift (1946). 2016 Oct;166(13-14):424-30. PubMed PMID: 27671008.

6. Sugano K, Tack J, Kuipers EJ, Graham DY, El-Omar EM, Miura S, et al. Kyoto global consensus report on Helicobacter pylori gastritis. Gut. 2015 Sep;64(9):1353-67. PubMed PMID: 26187502. 
7. Watari J, Chen N, Amenta PS, Fukui H, Oshima T, Tomita T, et al. Helicobacter pylori associated chronic gastritis, clinical syndromes, precancerous lesions, and pathogenesis of gastric cancer development. World journal of gastroenterology. 2014 May 14;20(18):5461-73. PubMed PMID: 24833876.

8. Nayak VH, Engin NY, Burns JJ, Ameta P. Hypereosinophilic Syndrome With Eosinophilic Gastritis. Global pediatric health. 2017;4:2333794X17705239. PubMed PMID: 28491930.

9. Rodriguez-Castro KI, Franceschi M, Miraglia C, Russo M, Nouvenne A, Leandro G, et al. Autoimmune diseases in autoimmune atrophic gastritis. Acta bio-medica: Atenei Parmensis. 2018 Dec 17;89(8S):100-3. PubMed PMID: 30561426.

10. Wei J, Nagy TA, Vilgelm A, Zaika E, Ogden SR, Romero-Gallo J, et al. Regulation of p53 tumor suppressor by Helicobacter pylori in gastric epithelial cells. Gastroenterology. 2010 Oct;139(4):133343. PubMed PMID: 20547161.

11. Mbulaiteye SM, Hisada M, El-Omar EM. Helicobacter Pylori associated global gastric cancer burden. Frontiers in bioscience (Landmark edition). 2009 Jan 1;14:1490-504. PubMed PMID: 19273142.

12. Al-hassany HA, Albu-rghaif AH, A. Naji M. Tumor diagnosis by genetic markers protein P-53, p16, CMYC, N-MYC, protein K-Ras, and gene her-2 Neu is this possible? Tumor diagnosis by genetic markers C-MYC, N-MYC, protein P-53, p16. Pakistan Journal of Medical and Health Sciences. 2021;15(8):2350-4.

13. Karam Turath Tawfeeq SHSA-T. P53 over-expression in urothelial carcinoma of the bladder: An Immunohistochemical Study. The Medical Journal of Tikrit University 2012;18(182):189-211.

14. Salih BA, Gucin Z, Bayyurt N. A study on the effect of Helicobacter pylori infection on p53 expression in gastric cancer and gastritis tissues. Journal of infection in developing countries. $2013 \mathrm{Sep}$ 16;7(9):651-7. PubMed PMID: 24042100.

15. Shadifar M, Ataee R, Ataie A, Heydari Gorgi AM, Nasri Nasrabadi N, Nouri S. Genetic and molecular aspects of Helicobacter pylori in gastritis, pre- cancerous conditions and gastric adenocrcinoma. Gastroenterology and hepatology from bed to bench. 2015 Spring;8(Suppl 1):S15-22. PubMed PMID: 26171133.

16. Sun X, Kaufman PD. Ki-67: more than a proliferation marker. Chromosoma. 2018 Jun;127(2):17586. PubMed PMID: 29322240.

17. Cabral MM, Oliveira CA, Mendes CM, Guerra J, Queiroz DM, Rocha GA, et al. Gastric epithelial cell proliferation and cagA status in Helicobacter pylori gastritis at different gastric sites. Scandinavian journal of gastroenterology. 2007 May;42(5):545-54. PubMed PMID: 17454874.

18. Ikenberg H, Bergeron C, Schmidt D, Griesser H, Alameda F, Angeloni C, et al. Screening for cervical cancer precursors with p16/Ki-67 dual-stained cytology: results of the PALMS study. Journal of the National Cancer Institute. 2013 Oct 16;105(20):1550-7. PubMed PMID: 24096620.

19. Petry KU, Schmidt D, Scherbring S, Luyten A, Reinecke-Lüthge A, Bergeron C, et al. Triaging Pap cytology negative, HPV positive cervical cancer screening results with p16/Ki-67 Dual-stained cytology. Gynecologic oncology. 2011 Jun 1;121(3):505-9. PubMed PMID: 21420158. 
20. Wentzensen N, Schwartz L, Zuna RE, Smith K, Mathews C, Gold MA, et al. Performance of p16/Ki-67 immunostaining to detect cervical cancer precursors in a colposcopy referral population. Clinical cancer research: an official journal of the American Association for Cancer Research. 2012 Aug 1;18(15):4154-62. PubMed PMID: 22675168.

21. Ahadi M, Moradi A, Musavinejad L, Movafagh A, Moradi A. The Expression of p53, CD44, Ki-67, and HER-2/neu Markers in Gastric Cancer and Its Association with Histopathological Indicators: A Retrospective Study. Asian Pacific journal of cancer prevention: APJCP. 2020 Jun 1;21(6):1607-14. PubMed PMID: 32592354.

22. Li N, Xie C, Lu N-H. p53, a potential predictor of Helicobacter pylori infection-associated gastric carcinogenesis? Oncotarget. 2016;7(40).

23. Mahmoudzadeh Sagheb H, Heidari Z, Jahantigh M, Narouei M. Immunohistochemical Expression of p53 and Ki-67 Genes in Gastric Cancer and Precancerous Lesions in the Patients with Helicobacter pylori Infection. Gene Cell Tissue. 2016;3(4):e41341. Epub 2016-08-02. en.

24. Tiwari E, AP, RM, SM. P53 and ki67 Immunostaining in Gastric Biopsies: A Histopathological Study. International Journal of Scientific Study 2015;2(11):96-101.

25. Azza Hegazi EH, Kamal A. El-Atrebi, and Hala T. El-Bassyouni. "P53 protein and Ki-67 expression in chronic gastritis patients with positive Helicobacter pylori infection" Journal of Genetic Engineering and Biotechnology. 2011.;9(1).

26. Gobbo César AC, de Freitas Calmon M, Cury PM, Caetano A, Borim AA, Silva AE. Genetic alterations in benign lesions: chronic gastritis and gastric ulcer. World journal of gastroenterology. 2006 Jan 28;12(4):625-9. PubMed PMID: 16489680.

27. Elnashar AT, ARA, MHM, GMK. Immunohistochemical Detection of P53 in Helicobacter Pylori Gastritis Cancer Biology. 2016;6(2):30-7.

28. Morales-Fuentes GA, Zarate-Osorno A, Quiñónez-Urrego EE, Antonio-Manrique M, Martínez-García CL, Figueroa-Barojas $\mathrm{P}$, et al. [p53 expression in the gastric mucosa of patients infected with Helicobacter pylori]. Revista de gastroenterologia de Mexico. 2013 Jan-Mar;78(1):12-20. PubMed PMID: 23374541.

29. Aziz ZW, Saleem SH, Al-Nuaimy HA. Helicobacter pylori in Gastric biopsy: A Histochemical and Immunohistochemical Assessment. Annals of the College of Medicine, Mosul. 2020;41(2):139-47.

30. Forones NM, Carvalho AP, Giannotti-Filho O, Lourenço LG, Oshima CT. Cell proliferation and apoptosis in gastric cancer and intestinal metaplasia. Arquivos de gastroenterologia. 2005 JanMar;42(1):30-4. PubMed PMID: 15976908.

\section{Tables}


(Table -1- Age distribution with Ki67 expression)

\begin{tabular}{|c|c|c|c|c|}
\hline Age groups (years) & No. & $\begin{array}{c}\text { Ki67 +ye } \\
\text { No. }(\%)\end{array}$ & $\begin{array}{c}\text { Ki67 -xe } \\
\text { No. (\%) }\end{array}$ & p-value \\
\hline$<28$ & 4 & $4(16.0)$ & $0(0.0)$ & \multirow{6}{*}{0.039} \\
\hline 28-41 & 6 & $5(20.0)$ & $1(20.0)$ & \\
\hline $42-55$ & 11 & $9(36.0)$ & $2(40.0)$ & \\
\hline $56-69$ & 5 & $4(16.0)$ & $1(20.0)$ & \\
\hline$\geq 70$ & 4 & $3(12.0)$ & $1(20.0)$ & \\
\hline Total & 30 & $25(100.0)$ & $5(100.0)$ & \\
\hline
\end{tabular}

(Table -2- Age distribution with P53 expression)

\begin{tabular}{|c|c|c|c|c|}
\hline Age groups (years) & No. & $\begin{array}{l}\text { P53 +ye } \\
\text { No. (\%) }\end{array}$ & $\begin{array}{l}\text { P53 - -ye } \\
\text { No. (\%) }\end{array}$ & p-value \\
\hline$<28$ & 4 & $4(16.0)$ & $0(0.0)$ & \multirow{6}{*}{0.019} \\
\hline 28-41 & 6 & $4(16.0)$ & $2(40.0)$ & \\
\hline $42-55$ & 11 & $10(40.0)$ & $1(20.0)$ & \\
\hline $56-69$ & 5 & $4(16.0)$ & $1(20.0)$ & \\
\hline$\geq 70$ & 4 & $3(12.0)$ & $1(20.0)$ & \\
\hline Total & 30 & $25(100.0)$ & $5(100.0)$ & \\
\hline
\end{tabular}




\begin{tabular}{|c|c|c|c|c|c|}
\hline \multicolumn{2}{|l|}{ Sydney system } & No. & Ki67 +ye & Ki67 -ye & p-value \\
\hline \multirow[t]{5}{*}{ Chronic Inflammation } & 0 & 1 & $0(0.0)$ & $1(20.0)$ & \multirow{5}{*}{0.014} \\
\hline & 1 & 5 & $3(12.0)$ & $2(40.0)$ & \\
\hline & 2 & 9 & $9(36.0)$ & $0(0.0)$ & \\
\hline & 3 & 15 & $13(52.0)$ & $2(40.0)$ & \\
\hline & Total & 30 & $25(100.0)$ & $5(100.0)$ & \\
\hline \multirow{5}{*}{ P.M.N. } & 0 & 5 & $2(8.0)$ & $3(60.0)$ & \multirow{5}{*}{0.227} \\
\hline & 1 & 7 & $7(28.0)$ & $0(0.0)$ & \\
\hline & 2 & 12 & $10(40.0)$ & $2(40.0)$ & \\
\hline & 3 & 6 & $6(24.0)$ & $0(0.0)$ & \\
\hline & Total & 30 & $25(100.0)$ & $5(100.0)$ & \\
\hline \multirow[t]{5}{*}{ Atrophy } & 0 & 4 & $1(4.0)$ & $3(60.0)$ & \multirow{5}{*}{0.131} \\
\hline & 1 & 7 & $7(28.0)$ & $0(0.0)$ & \\
\hline & 2 & 13 & $11(44.0)$ & $2(40.0)$ & \\
\hline & 3 & 6 & $6(24.0)$ & $0(0.0)$ & \\
\hline & Total & 30 & $25(100.0)$ & $5(100.0)$ & \\
\hline \multirow[t]{5}{*}{ Metaplasia } & 0 & 28 & $24(96.0)$ & $4(80.0)$ & \multirow{5}{*}{0.013} \\
\hline & 1 & 1 & $0(0.0)$ & $1(20.0)$ & \\
\hline & 2 & 1 & $1(4.0)$ & $0(0.0)$ & \\
\hline & 3 & 0 & $0(0.0)$ & $0(0.0)$ & \\
\hline & Total & 30 & $25(100.0)$ & $5(100.0)$ & \\
\hline
\end{tabular}


(Table -4- Sydney system with P53 expression)

\begin{tabular}{|c|c|c|c|c|c|}
\hline \multicolumn{2}{|l|}{ Sydney system } & No. & P53 + ye & P53 - ye & p-value \\
\hline \multirow{5}{*}{ Chronic Inflammation } & 0 & 1 & $0(0.0)$ & $1(20.0)$ & \multirow{5}{*}{0.020} \\
\hline & 1 & 5 & $2(8.0)$ & $3(60.0)$ & \\
\hline & 2 & 9 & $8(32.0)$ & $1(20.0)$ & \\
\hline & 3 & 15 & $15(60.0)$ & $0(0.0)$ & \\
\hline & Total & 30 & $25(100.0)$ & $5(100.0)$ & \\
\hline \multirow[t]{5}{*}{ P.M.N. } & $\mathbf{0}$ & 5 & $2(8.0)$ & $3(60.0)$ & \multirow{5}{*}{0.110} \\
\hline & 1 & 7 & $6(24.0)$ & $1(20.0)$ & \\
\hline & 2 & 12 & $11(44.0)$ & $1(20.0)$ & \\
\hline & 3 & 6 & $6(24.0)$ & $0(0.0)$ & \\
\hline & Total & 30 & $25(100.0)$ & $5(100.0)$ & \\
\hline \multirow{5}{*}{ Atrophy } & 0 & 4 & $1(4.0)$ & $3(60.0)$ & \multirow{5}{*}{0.078} \\
\hline & 1 & 7 & $5(20.0)$ & $2(40.0)$ & \\
\hline & 2 & 13 & $13(52.0)$ & $0(0.0)$ & \\
\hline & 3 & 6 & $6(24.0)$ & $0(0.0)$ & \\
\hline & Total & 30 & $25(100.0)$ & $5(100.0)$ & \\
\hline \multirow[t]{5}{*}{ Metaplasia } & 0 & 28 & $23(92.0)$ & $5(100.0)$ & \multirow{5}{*}{0.034} \\
\hline & 1 & 1 & $1(4.0)$ & $0(0.0)$ & \\
\hline & 2 & 1 & $1(4.0)$ & $0(0.0)$ & \\
\hline & 3 & 0 & $0(0.0)$ & $0(0.0)$ & \\
\hline & Total & 30 & $25(100.0)$ & $5(100.0)$ & \\
\hline
\end{tabular}

Figures 

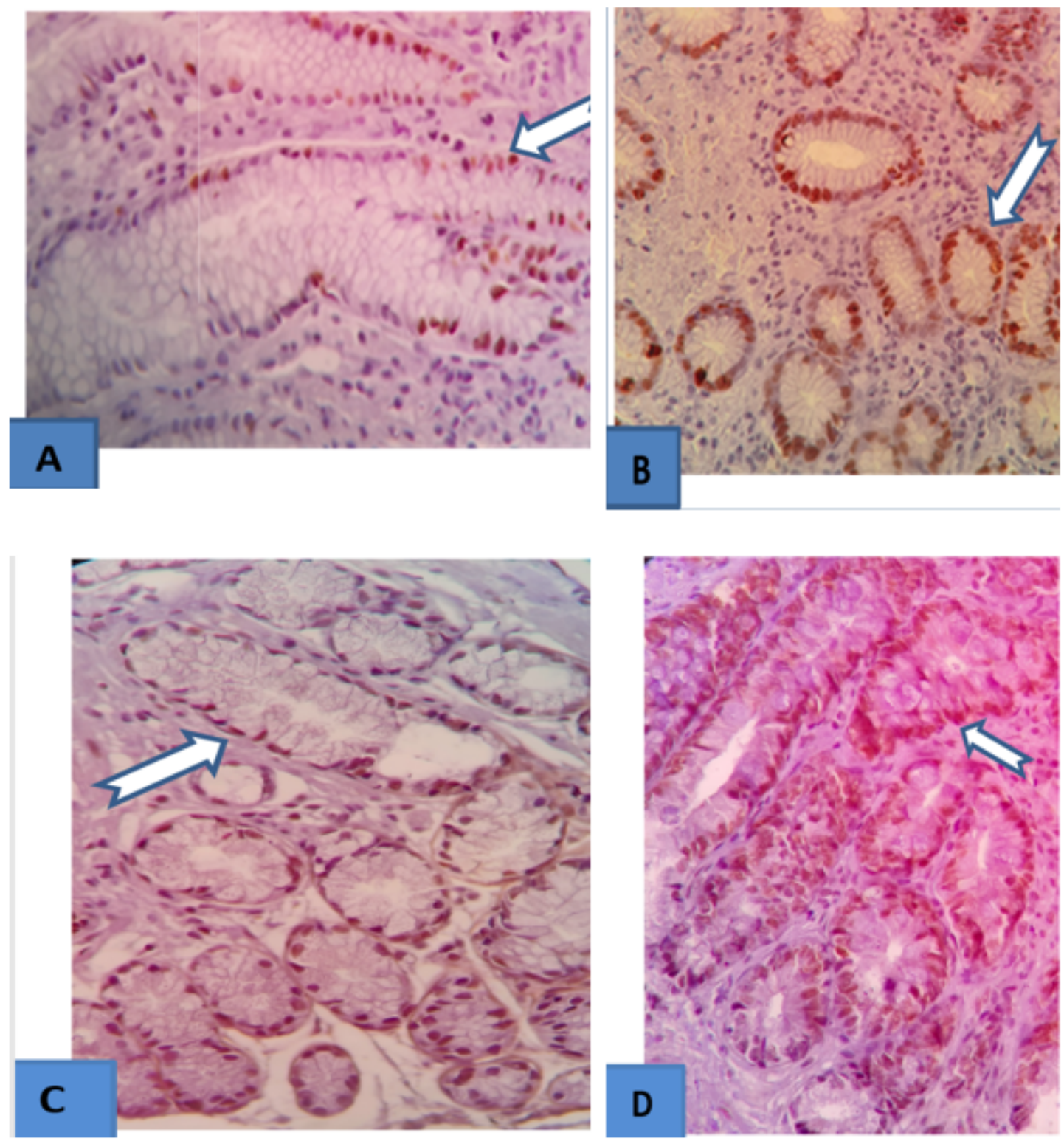

\section{Figure 1}

H. pylori positive gastritis with weak Ki-67 expression magnification-400. shows four cases with weak and strong expression of Ki67 and P53 expression in this figure (A) , strong Ki-67 expression (B); weak P53 expression (C) and strong P53 expression (D) appeared as brown colour (arrows) magnification-400. 


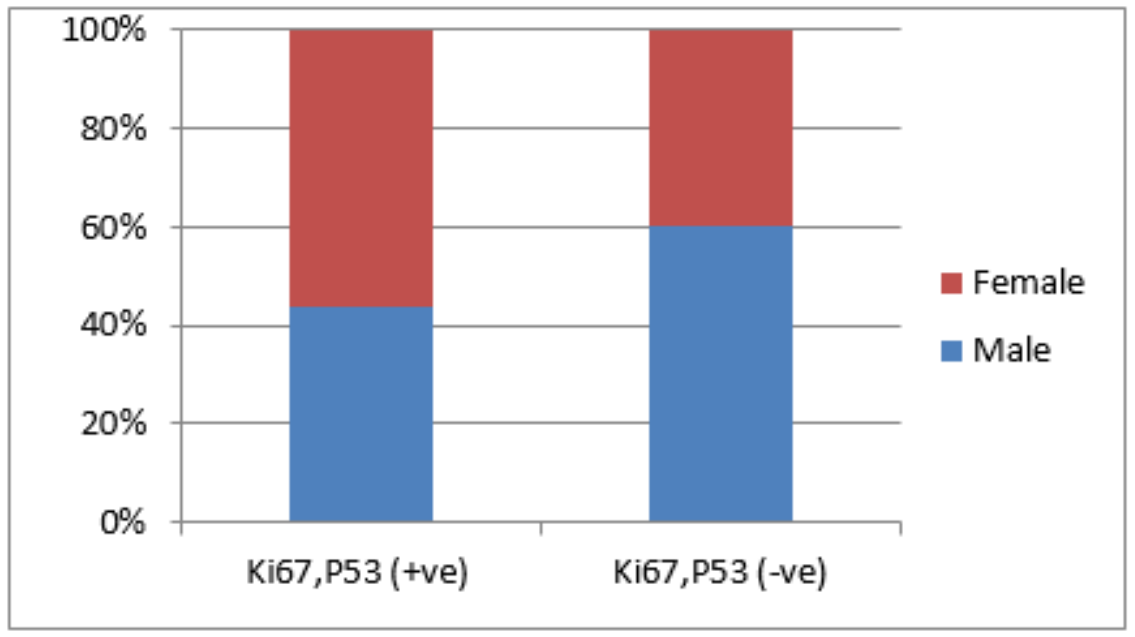

Figure 2

Sex distribution with Ki67, P53 expression, p-value (0.409)

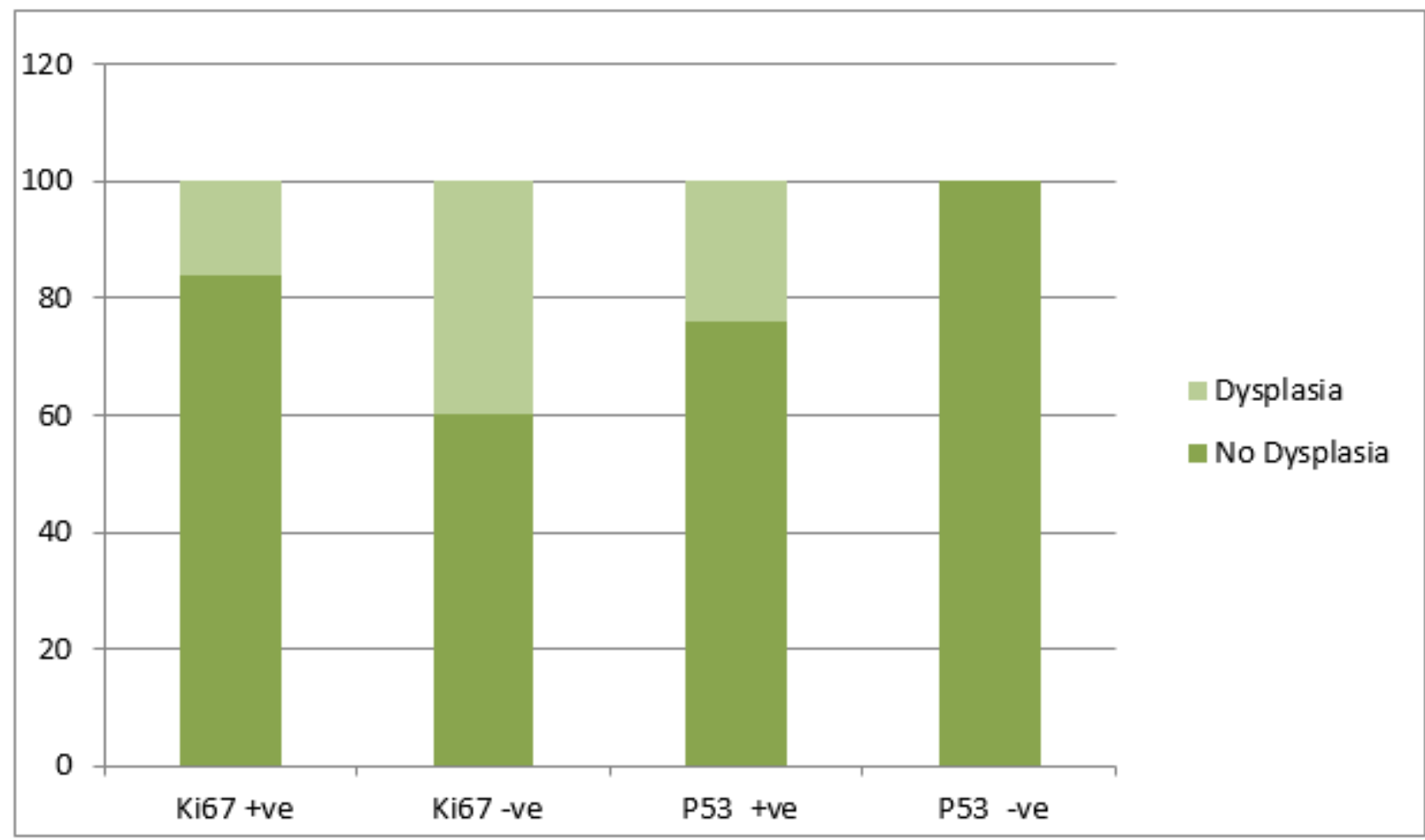

Figure 3

Dysplasia with Ki67 expression: p-value (0.074), P53 expression: p-value (0.467) 